\title{
El aporte educativo de una estética de la andinidad: consideraciones sobre una reciente investigación filosófica y literaria
}

Fernando G. Martin-de-Blassi*

Becario doctoral por el Consejo Nacional de Investigaciones Científicas y Técnicas y por la Confederación Suiza. Profesor y licenciado en Filosofía, Facultad de Filosofía y Letras, Universidad Nacional de Cuyo, Mendoza, Argentina. Correo electrónico: martindeblassi@hotmail.com

Recibido: 14 de diciembre del 2015 Aprobado: 2 de marzo del 2016

Cómo citar este artículo: Martin-de-Blassi, Fernando G. "El aporte educativo de una estética de la andinidad: consideraciones sobre una reciente investigación filosófica y literaria". Rastros Rostros 18.32 (2016): 7786. Impreso. doi: http://dx.doi.org/10.16925/ ra.v18i32.1426.

\section{Resumen}

Propósito: en este artículo se busca reflexionar críticamente sobre los temas y las ideas propuestas por Liliana Mannina de Gamero en El silencio andino: huella de identidad. Hacia una estética de la andinidad. Descripción: se privilegia la metodología hermenéutica, que consiste en interpretar textos seleccionados para su análisis, a partir de los cuales se intenta descubrir los diversos niveles de comprensión articulados en el estudio de Mannina de Gamero, los interrogantes que plantea y las problemáticas suscitadas a raíz de tales cuestiones. Punto de vista: la estética de la autora se establece a partir de un análisis crítico de los aportes humanísticos de tres poetas argentinos: Juan Draghi Lucero, Manuel J. Castilla y Héctor D. Gatica. El presente artículo no se limita a un público especializado, sino que busca estimular la lectura placentera de estos tres poetas. Conclusiones: el enfoque elaborado por Mannina de Gamero acerca de la estética de la andinidad contribuye a replantear, sobre la base conceptual del binomio poetizar y pensar, la pregunta existencial por la identidad y el reconocimiento histórico que presupone todo fenómeno educativo situado en América Latina.

Palabras clave: estética de la andinidad, identidad, reconocimiento, silencio. 


\title{
The Educational Contribution of an Aesthetic of Andeanness: Considerations on a Recent Philosophical and Literary Research Study
}

\begin{abstract}
Aim: This article seeks to critically reflect on the issues and ideas proposed by Liliana Mannina de Gamero in Andean Silence: Marker of Identity. Towards an aesthetic of Andeanness. Description: Priority is given to a methodology of hermeneutics, which consists of interpreting selected texts in order to analyze them. These texts were selected in an attempt to uncover the various levels of understanding articulated in the study by Mannina de Gamero, the questions she poses, and the issues that arise as a result of this questioning. Point of view: The aesthetic of the author is established through a critical analysis of the humanistic contributions of three Argentinian poets: Juan Draghi Lucero, Manuel J. Castilla, and Héctor D. Gatica. This article is not limited to a specialized audience but rather seeks to stimulate the pleasurable reading of these three poets. Conclusions: The approach developed by Mannina de Gamero about the aesthetic of Andeanness contributes to the reassessment, on the conceptual basis of the relationship between writing poetry and thinking, of the existential question of identity and historical recognition presupposed by every educational phenomenon in Latin America.
\end{abstract}

Keywords: aesthetic of Andeanness, identity, recognition, silence.

\section{A contribuição educativa de uma estética da andinidade: considerações sobre uma recente pesquisa filosófica e literária}

\section{Resumo}

Propósito: neste artigo procura-se refletir criticamente sobre os temas e as ideias propostas por Liliana Mannina de Gamero em O silêncio andino: marca de identidade. Rumo a uma estética da andinidade. Descrição: privilegia-se a metodologia hermenêutica, que consiste em interpretar textos selecionados para sua análise, a partir dos quais se tenta descobrir os diversos níveis de compreensão articulados no estudo de Mannina de Gamero, os interrogantes que apresenta e as problemáticas suscitadas como resultado de tais questões. Ponto de vista: a estética da autora estabelece-se a partir de uma análise crítica das contribuições humanísticas de três poetas argentinos: Juan Draghi Lucero, Manuel J. Castilla e Héctor D. Gatica. O presente artigo não se limita a um público especializado, mas procura estimular a leitura prazerosa desses três poetas. Conclusões: o enfoque elaborado por Mannina de Gamero acerca da estética da andinidade contribui para repensar, sobre a base conceitual do binômio poetizar e pensar, a pergunta existencial pela identidade e pelo reconhecimento histórico que pressupõe todo fenômeno educativo situado na América Latina.

Palavras-chave: estética da andinidade, identidade, reconhecimento, silêncio. 


\section{Introducción}

El propósito del presente artículo es analizar la estructura y el contenido de una reciente investigación filosófica acerca de la obra literaria de tres autores inscritos en la tradición del canto popular, a saber, Juan Draghi-Lucero, Manuel J. Castilla y Héctor D. Gatica. El estudio al cual me refiero se titula $E l$ silencio andino: huella de identidad. Hacia una estética de la andinidad, y es una publicación en español de Liliana Mannina de Gamero, quien se desempeña como docente e investigadora de la Facultad de Filosofía y Letras de la Universidad Nacional de Cuyo (Argentina). En lo fundamental, la importancia del trabajo de Mannina de Gamero está en cómo ella limita su objeto de estudio y cómo encauza su posterior análisis, articulándolo en función del corpus de los tres autores mentados. Desde el inicio mismo de su escrito, Mannina de Gamero se aboca con acierto y precisión al diseño de una estética que designa con el nombre de estética de la andinidad, a fin de mostrar hasta qué punto sus categorías teóricas no solo se adecuan, sino que además configuran de modo eficaz, la impronta poética de los documentos seleccionados para su examen. Esto significa que la estética en cuestión ahonda en las cualidades estilísticas de este género peculiar protagonizado por la poesía popular en la medida en que sus categorías operan como funciones de unidad, y permite al mismo tiempo garantizar el carácter unitario de los elementos discursivos utilizados por cada uno de los tres escritores. En este sentido, si bien existían estudios particulares de literatura dedicados a los autores, la ponderación que lleva a cabo Mannina de Gamero constituye en cambio un enfoque significativo en materia filosófica y literaria, por ser la primera vez que en Argentina se examinan las obras de Draghi, Castilla y Gatica no tanto en relación con la crítica literaria en curso, sino más bien con el andamiaje especulativo que las posibilita. El trabajo de Mannina de Gamero se establece entonces como una referencia obligada para futuras investigaciones sobre la literatura argentina contemporánea, particularmente aquellas que versen sobre la tradición folclórica y popular.

Hay que aclarar que este artículo es una reflexión axiológica sobre los aportes de la estética de Mannina de Gamero. La hipótesis de este es que el estudio elaborado por la autora acerca de la estética de la andinidad contribuye a replantear la pregunta existencial por la identidad y el reconocimiento histórico de todo proyecto educativo situado en América Latina, teniendo en cuenta la influencia mutua entre poetizar y pensar. En sentido estricto, Martin Heidegger introduce los términos de poetizar y de pensar en su estudio acerca del lenguaje de la última etapa de su desarrollo filosófico, que va de 1936 a 1938, cuando publicó Aportes a la filosofía: Acerca del evento, que la crítica considera como la segunda gran obra después de Ser y tiempo. Aunque en esta última obra ya se había mostrado una conexión esencial entre ser y lenguaje (Ser y tiempo, \$34), toda vez que la verdad del ser acontece en el lenguaje, en el último período, empero, se observa un giro en el cual el filósofo ya no pregunta por el sentido del ser, sino que plantea la necesidad de una transformación radical del pensar en virtud de la apropiación mutua entre el arte (poetizar) y la filosofía (pensar). Ante la necesidad de superar el pensar metafísico occidental, que procede según el modo de ser de la esencia de la técnica, la experiencia del lenguaje como morada del ser cumple para Heidegger un destino ciertamente inusitado, puesto que el lenguaje asume una dimensión ajena a toda otra consideración psicológica, histórica o científica que pudiera efectuarse sobre este. La pregunta de partida de Heidegger es cómo acontece el lenguaje en cuanto tal, que es una cuestión directa sobre lo propio de este y no por el mecanismo de su evolución filo u ontogenética, así como tampoco por su fundamentación a partir de la ciencia ni mucho menos por su aspecto comunicativo o el su papel en la interacción de los hablantes. Por su parte, Heidegger ve en el camino hacia la esencia del lenguaje la posibilidad para experimentar el despliegue de la palabra fundadora a fin de que el ser humano existente pueda habitar nuevamente la tierra, dado que el lenguaje en cuanto tal constituye la esencia originaria del ser histórico del hombre. La poesía, que es la obra distinguida del lenguaje, determina aquella posibilidad del acontecer como fundación y apropiación simultáneas del mundo.

Si bien el núcleo de la dupla poetizar y pensar corresponde a una meditación heideggereana, esto no obsta para que también se puedan aplicar para caracterizar el enfoque de Mannina de Gamero, de acuerdo con los cánones de la andinidad, elemento estético de la poesía de Draghi, Castilla y Gatica. En este punto conviene especificar que la relación entre poetizar y pensar atañe igualmente a la cuestión educativa, entendiendo por educativa no solo una práctica que satisface demandas y necesidades sociales, 
que sigue determinadas políticas públicas nacionales o regionales, que convalida el avance científico, sino a una pregunta por el desarrollo y fortalecimiento de la formación integral del ser humano a lo largo de toda su vida que promueve una capacidad de definir para sí un proyecto de vida auténtico conforme con su dignidad y cimentado en los valores de la libertad, la paz, la solidaridad, la justicia, la responsabilidad, el bien común, entre otros (art. 8 de la Ley de Educación Nacional 26.206 de la República de Argentina).

Sobre la base de este marco conceptual, mi investigación no problematiza un fenómeno educativo concreto, sino que busca plantear interrogantes acerca de la condición existencial en la que interactúan cada uno de los actores involucrados en la práctica educativa. En este sentido, puede decirse que la presente contribución es sobre las condiciones de posibilidad humanas de un acto educativo, en la medida en que se lo comprenda como actividad libre y autoconsciente de la subjetividad. Más allá de las diversas instituciones y realidades a que pertenece cada uno durante su proceso de enseñanza-aprendizaje, hay preguntas fundamentales, ineludibles, que solo la filosofía puede formular y que congregan a todos, sin importar las particularidades culturales en las que cada uno haya sido instruido: ¿quién soy?, ¿de dónde vengo?, ¿es posible una vida justa?, ¿en qué medida lo es?, ¿qué es la felicidad?, ¿se puede alcanzar?, ¿tiene sentido una vida feliz?, ¿vamos indefectiblemente hacia la muerte?, ¿qué es la muerte? La propuesta de Mannina de Gamero a propósito de la obra poética de los autores andinos permite reflexionar en torno al sentido de todo acto educativo y la esperanza que se tiene sobre este, en la cual la condición existencial del ser humano se muestra abierta a la perfección y al desarrollo de múltiples competencias en la interacción dinámica con otros. Mi interés, por tanto, es previo a toda otra determinación que pudiese adoptar el proceso educativo, haciendo valer la posibilidad fundamental de acometer el imperativo del reconocimiento en un tiempo y espacio concretos. Por eso, mi análisis no se restringe a una sola porción de las modalidades educativas, ni a cualquiera de las trayectorias implicadas en el ámbito de la educación formal, ni tampoco a alguno de los múltiples perfiles de los actores comprometidos con el quehacer educativo, ni mucho menos a alguna de sus dimensiones humanas como la ética, la psicológica o la comunicativa.
En lo que respecta a la metodología de este trabajo, conviene precisar algunos detalles. Puesto que mi objetivo es ponderar una investigación ya realizada, este artículo es de reflexión. Para ello, pretendo realizar un análisis cualitativo de la obra escrita por Mannina de Gamero intentando seguir una vía media que no se reduzca a la mera paráfrasis ni a una sinopsis genérica del texto. En vista de esta propuesta, haré dialogar a Mannina de Gamero con otros filósofos contemporáneos de la corriente hermenéutica y narrativa, en orden de elucidar y valorar los aportes educativos y literarios de la estética de la autora. Se privilegia, por consiguiente, el uso de una metodología hermenéutica, que consiste en interpretar textos para su análisis. En este sentido, se intenta descubrir los diversos niveles de comprensión articulados en el estudio de Mannina de Gamero, los interrogantes que plantea y las problemáticas suscitadas a la luz de tales cuestiones. En vista de este procedimiento, se acude también al apoyo instrumental de una bibliografía especializada del ámbito científico y académico. Los diversos aspectos extraídos a partir de esta exégesis se desarrollan en los subtítulos que fijan el derrotero de este trabajo. Con todo, el presente artículo no pretende circunscribirse a un público especializado, sino que asume al deseo de estimular la lectura placentera de los tres poetas: Draghi, Castilla y Gatica. Para esto se define como un instrumento de referencia abierta sobre las novedades de una estética de la andinidad, junto con las observaciones fructíferas que en materia formativa brinda el libro de Mannina de Gamero.

\section{Fundamento y estructura de El silencio andino}

El informe de investigación escrito por Mannina de Gamero se organiza de la siguiente manera: comienza con un prólogo escrito por la Dra. Marta Castellino y una introducción; se demarca luego un núcleo específico de categorías relativas a una estética de la andinidad, a fin de reconocer su operatividad en un corpus literario seleccionado sobre la base de un criterio geográfico y cultural, atento a los grandes focos de la tradición andina. El eje conceptual que guía la investigación de marras lo constituye el tema del silencio por ser un baluarte simbólico del acervo espiritual, para preservar el significado vital de la existencia humana. La complejidad que entraña la tarea de amalgamar un análisis literario propiamente dicho y brindar un encuadre filosófico de esta exégesis reclama la importancia de acertar en la 
temática, el método y las tesis centrales sostenidas en un trabajo semejante. En el caso del libro de Mannina de Gamero, estos tres elementos han sido felizmente escogidos y desarrollados con exactitud.

Ante todo, la temática no puede ser de mayor interés, pues concierne a una materia significativa para la literatura argentina en general y contemporánea en particular. Por lo demás, la obra de los autores seleccionados atañe a una poesía gestada al amparo de las tradiciones populares, que toma de ellas su propia identidad. Esto tiene una importancia medular porque la originalidad del trabajo no radica tanto en sumar una serie de aportes descriptivos o historiográficos a la investigación literaria ya en curso como en ponderar la obra poética de los autores citados desde el sustrato que posibilita su misma producción artística. Según advierte Mannina de Gamero, este foco donde se nutre el acaecer poético de Draghi-Lucero, Castilla y Gatica estriba en la categoría de identidad entendida como ipseidad. A partir de este nivel, se mide tanto la importancia como la pertinencia de la presente investigación y su correspondiente alcance. De acuerdo con esto, Mannina de Gamero procura descubrir, dentro de un campo literario previamente delimitado, funciones de unidad que contribuyan a la consecución de su objetivo fundamental, esto es, entender a la ipseidad como un núcleo de múltiples sistemas de significancia: del mito, del arte, de la religión y de la filosofía. Así mismo, se busca descubrir el vínculo de la ipseidad con el horizonte del reconocimiento (21).

El método seguido por Mannina de Gamero es una interpretación de textos poéticos dentro de una tradición de pensamiento, que es por lo demás la mejor manera de acercarse a la meditación filosófica. Esto es así toda vez que solo se puede pensar de manera fructífera en el marco de una tradición de pensamiento, tal como lo ha mostrado con feliz acierto MacIntyre, al decir que

La posesión y la transmisión de esta especie de capacidad de reconocer en el pasado lo que es y lo que no es una guía para el futuro, es lo que se halla en el núcleo de una tradición adecuadamente encarnada [...]. Un pensamiento de buenas condiciones tiene que estar encarnado en una tradición que esté en buenas condiciones. (167)

Pretender un sistema de pensamiento a partir de cero y con las características de una originalidad absoluta está abocado de antemano al fracaso y, cuando no, al absurdo. Al abrazar el verbo poético y el pensar filosófico, Mannina de Gamero considera que esto no puede hacerse desde una metodología extrínseca al mismo pensar. Ella se enmarca explícitamente en el sistema de la narración histórica o de la filosofía narrativa (22ss.). Por esto, la pareja conceptual de poetizar y pensar comprende el elemento con el cual Mannina de Gamero aprovecha al máximo las virtualidades presentes en la tradición de los poetas que cantan y las relaciona en el fragmento que ha seleccionado para efectuar su análisis. Se trata de una línea de pensamiento viva y eficaz que presenta diversas corrientes internas, se desarrolla y actualiza en el tiempo y dialoga activamente con las restantes posiciones filosóficas. Esto permite, a su vez, que al tratar ciertos temas -como el silencio, el canto popular y la belleza estética de lo andino, que se aprecian en la obra de Draghi-Lucero, Castilla y Gatica- Mannina de Gamero suponga no solo el provecho de la crítica literaria realizada sobre estos, sino también el resultado no menos fecundo que pueda brindar un debate con las principales de las propuestas formuladas por la filosofía contemporánea.

Por otra parte, al adoptar un enfoque interdisciplinar sobre el canto de los tres poetas andinos ya citados, la autora orienta su estudio respondiendo al principio hermenéutico de la productividad histórica. Esto es posible en cuanto se advierte en la permanencia de toda tradición una vital apertura a reinterpretaciones y reapropiaciones respecto de un potencial de sentido. Esta sedimentación es susceptible de ser siempre actualizada en favor de la consciencia ética y estética de los pueblos, que proyectan su identidad desde el legado tradicional. La impronta identitaria - considera Mannina de Gamero $(22-23,29)$ - se vigoriza desde las tradiciones de sentido de las comunidades, que encuentran en el canto y la poesía popular la clave para una integración cultural plausible. Se destaca el significado que adquiere en el campo literario la poesía tradicional, pues se confirma el testimonio de Menéndez Pidal: “[...] la poesía popular es de un autor que se siente pueblo [...] la poesía tradicional es una poesía de un pueblo que se hace autor" (citado por Becco 34).

\section{Tesis centrales de El silencio andino}

\section{La recuperación del tema de la identidad}

En primer lugar, Mannina de Gamero observa que la vigencia de la problemática en torno a la identidad 
es incuestionable, y, a causa de este hecho, se hace cargo del tema del sí mismo y de su estructura temporal. Para alcanzar estos fines, la autora realiza un ensayo alternativo para volver a los horizontes del ser y del êthos tanto sociales como personales. En virtud de esta aproximación, Mannina de Gamero (23ss.) acepta el binomio idem-ipse, propuesto por Ricœur, para dimensionar el alcance semántico de la identidad comprendida en términos de ipseidad.

Tales conceptos conciernen, por un lado, a la intensidad y, por otro, a la definición de una identidad formal, sustancial, singular y encapsulada en una temporalidad cuasifísica. Pero también corresponde a una identidad narrativa, es decir, a una reflexiva unidad aperceptiva de acciones, deseos, sentimientos y voliciones, que puede ser conjugada en los pronombres personales y cuyo trasunto abarca un tiempo humano capaz de configurarse por medio de la experiencia de la presencia. Para Ricœur - observa Mannina de Gamero (23-24) - la función de la identidad narrativa consiste en mediar entre la inventiva de la historia y la producción histórica de la ficción, en orden de superar dicotomías alienantes y asumir, en consecuencia, una temporalidad y sentido (Ricœur, Tiempo y narración; "La identidad narrativa").

La idea de ipseidad es plasmada por Ricœur a partir de la teoría hermenéutica de la narración y del principio aristotélico de la acción. Tales doctrinas corrigen el estructuralismo y la filosofía analítica en cuanto amplían las mediaciones del texto literario a partir de la capacidad figurativa del lenguaje $y$, por su parte, del poder configurador de la razón práctica. La imaginación productiva (poiética) es el agente directo del texto literario, y su efecto repercute, asimismo, en el plano ético. Precisamente, en la medida en que el texto literario como un producto imaginario y artístico se convierte en una experiencia cabal del pensamiento y del lenguaje, no se escapa de su compromiso con el acontecer del mundo (Mannina de Gamero 24).

En esta relación entre la ética y la narración, la experiencia de la identidad es un reconocimiento. Acompañado de la convicción de juzgar bien y vivir bien en comunidades justas, el reconocimiento propiamente dicho se pone en juego en virtud del íntimo reclamo que entraña el testimonio de sí. Mannina de Gamero (24-25) arguye que la función utópica de la imaginación productiva constituye el auténtico conatus para la voluntad, más aún, para una poética de la voluntad atenta al deseo, a la teleología y a la libertad, cuyo cumplimiento se canaliza en la justicia, en la felicidad y en la hermandad (Ricœur, Ideología y utopía 26ss.).

Ante lo ipse, se asiste a un proceso dialéctico de innovación y sedimentación, que manifiesta la actividad constitutiva de lo otro, de los otros y del Otro en una conformación espiritual, personal y comunitaria (Mannina de Gamero 25-26). En esta hermenéutica de la identidad, la fórmula del "sí mismo en cuanto otro" sugiere que la ipseidad lleva primeramente a la noción de alteridad en un grado tan íntimo que la una no puede dejar de pensarse sin la otra (Ricœur, Sí mismo como otro XIV). La toma de consciencia del sí mismo ha sido uno de los ideales más descollantes y preclaros que ha configurado la matriz occidental. Esto fue enunciado en los albores de la filosofía griega con el mandato délfico de gnôthi seautón; una reformulación de este legado en el contexto de la praxis y el filosofar latinoamericanos lo revela la expresión de "a priori antropológico", entendida así: “[...] ponernos para nosotros y valer sencillamente para nosotros" (Roig 17).

\section{El horizonte del reconocimiento}

En otro orden de ideas, Mannina de Gamero califica el horizonte del reconocimiento como la "[...] metáfora viva de la identidad" (24-25). La autora estima que el reconocimiento habilita la posibilidad de remontarse hacia acontecimientos fundacionales constitutivos de la memoria social, a fin de cooperar en la conformación de una identidad colectiva. La sustancia de esta densidad simbólica la representa un fondo temporal que confiere la potencia de ser, a la vez memoria y promesa, es decir, reestructura la experiencia instaurando una nueva manera de habitar el mundo (Ricœur, Caminos de reconocimiento 304). Desde esta óptica, se puede remontar - como alternativa comunitaria - el horizonte de la eticidad perdida que se ha extraviado en el sistema del trabajo alienado, de la sociedad de consumo, de las relaciones de poder $y$, finalmente, de la guerra.

A partir del horizonte del reconocimiento, la autora presenta los conceptos contrapuestos de silencio y de voz como categorías explicativas que actúan a modo de clave de bóveda de todo el desarrollo expositivo de su estudio (30-31). Esta primera demarcación revela un acierto metodológico en el trabajo de Mannina de Gamero, pues se corresponde de manera coherente con la ulterior exégesis de las obras de Draghi-Lucero, Castilla y Gatica en torno al asunto de la ipseidad. El núcleo identitario se formaliza en 
una estética que la autora denomina con el genitivo de "de la andinidad", apelando mediante esto a un feliz tino idiomático que hay - si bien no de manera excluyente- en las obras teóricas de Draghi-Lucero sobre el folclor cuyano.

\section{La conformación teórica de una "estética de la andinidad"}

La andinidad como tal está representada, según Mannina de Gamero (21-22), en los versos de ciertos autores, quienes pueden ser ubicados, dentro de la literatura argentina, como miembros de las generaciones del 25, del 40 y del 60 del siglo xx. Asimismo, en relación con el papel medular que juega el silencio dentro de esta estética, de cuño eminentemente americano y regional, Mannina de Gamero señala que el silencio no implica una retracción al vacío del ser - una ausencia de palabra-, sino que es un espacio vital abierto a la experiencia del reconocimiento. Este locus consiste en la condensación de todo aquello que designa el abismo de la libertad vislumbrado, por su parte, a través de las imágenes de la piedra, de la soledad y del indio.

La asunción de la obra de los poetas mencionados le permite a Mannina de Gamero regionalizar su propuesta inquisitiva y alcanzar, así, la universalidad de lo afincado. Esto es así toda vez que al definir algo o delimitar un género según su diferencia específica, se especifica su esencia de manera afirmativa y universal. Así lo explica Aristóteles, al decir que "[...] la definición es el enunciado constituido a partir de las diferencias" (Met. 1038a 28-29) y que uno de los significados convenientes al concepto de límite corresponde, por cierto, al de "[...] entidad, es decir, la esencia de cada cosa: esta es, en efecto, límite del conocimiento y si los es del conocimiento, también lo es de la cosa" (Met. 1022a 8-10). Por esto, los términos de universal y regional no deben entenderse como antitéticos, pues la universalización de lo regional es el resultado final del tratamiento de las realidades inmediatas. Todo autor vincula de manera significativa y personal la querencia regional, por un lado, y el alma universal, por otro (Barcia 46).

La trama, sobre cuya base lo andino teje sus múltiples sistemas de significancia, se muestra primero dentro del espacio literario stricto sensu. Aquí, una obra de arte se determina como un combate por la desocultación del sentido, que intenta salir victorioso, ya sea en las formas de constitución del existir, ya sea en los horizontes de posibilidad del mundo. De esta manera, una obra aparece como instancia poiética, es decir, experiencia de la libertad creadora, operante desde un material que no puede permanecer ajeno a la vivencia histórica ni tampoco al significado insignificable (Mannina de Gamero 45-48).

La autora (37-40) infiere que la cronotopía andina, bosquejada como uno de los elementos configuradores de la correspondiente estética, comprende un momento tanto de plenitud fundacional indígena como de oscurecimiento, representado esto último por la constitución de las distintas nacionalidades. Esta etapa, sustentada en un discurso ilustrado y de un modelo europeizante, se caracteriza por el desplazamiento de la ruta del Pacífico hacia el Atlántico. En semejante realidad geográfica, Mannina de Gamero recalca la inscripción de procesos históricos y culturales que dan como resultado un êthos o presente consolidado por el esfuerzo sostenido, el dolor, la paciencia de la contradicción y la extensión, más o menos lograda, a las alturas de la excelencia de lo propio.

Por otra parte, esta estética se particulariza en función de tres notas que Mannina de Gamero (4850) enumera de la siguiente manera: (a) el sentir americano, (b) la voluntad de región y (c) la conciencia folclórica.

\section{El sentir americano}

La primera de estas notas es un americanismo transmoderno, producto de un periodo que comienza en las últimas décadas del siglo xix con la demarcación de territorio, implicada en la consolidación de los estados nacionales. El nativismo, habiendo sido impuesto como modelo hegemónico, entra en crisis en las primeras décadas del siglo xx y se profundiza con el propio entorno, propiciado por la decantación en vertientes estéticas denominadas posmodernistas. Expone Mannina de Gamero:

El desenlace, ya en los albores de la década del [veinte], será la incorporación canónica del caudillo y el gaucho, el interior y la Patria grande [...]. La integridad buscada y oficializada por tal nacionalismo y su estética se reescribirá y profundizará, intensiva y extensivamente, en el transcurso de la década siguiente, el de la generación bifronte, y ya en el marco de la consolidación vanguardista. (50)

Estos lemas revelan una situación de la existencia humana que hace visible el esfuerzo por superar 
el ser europeo a fin de posicionarse en las raíces del estar americano ancestral. Esta situación se desenvuelve como un retroproyectarse desde un saber de vida, cultivado en un suelo social históricamente producido y que busca salvaguardar el reconocimiento de lo propio (Kush 84ss.).

\section{La voluntad de región}

Por lo que atañe a este segundo elemento, Mannina de Gamero (51-52) reconoce en cada uno de los autores tratados un ámbito privilegiado de autoconsciencia: el desierto lavallino, en el caso de Draghi-Lucero; los llanos riojanos, en la obra de Gatica, y la región de fronteras móviles, apreciable en Castilla. Tomando como referencia la metáfora de un espacio umbilical (omphalós), ella interpreta cada uno de esos lugares como puntos míticos de religación con lo uno primordial.

En los tres autores escogidos por Mannina de Gamero (29-30), el retorno a la unidad de la procedencia temporal originaria se revela como filiación del poeta al canto de la tradición y al ser que la sustenta, la tierra. Esta religación alcanza una dimensión literaria cuando se conjugan, en apretada síntesis, el interés creativo y el compromiso vital del escritor con la cultura de la ipseidad. La literatura de la tierra, en lugar de denotar una reducción a lo paisajístico o costumbrista, es expresión del alma de un pueblo como su voz atávica; tiene una larga historia de tradición oral y mantiene su persistencia en la literatura escrita, cuya dimensión sustancial consiste en "[...] la celebración de la naturaleza y el paisaje propios, el arraigo, el sentimiento de pertenencia a una geografía, y el culto a la tierra sagrada, Pacha Mama, sustentado en la tradición indígena" (Dávalos 16).

\section{La conciencia folclórica}

De esto abreva también la llamada "consciencia folclórica" (Mannina de Gamero 52-56) como una manifestación de la cultura popular, empírica, colectiva, oral, anónima, localizada y funcional (Cortázar 69ss.). El folclor es un horizonte mediado por sus proyecciones de sentido, que revela una fuerza centrípeta en la cual el poeta se encuentra con su pueblo y su peculiar modo de estar en el mundo, para testimoniar con su canto un proyecto literario integral. Asevera Mannina de Gamero (53-54) que los autores analizados por ella apoyan la literatura en la lírica de tradición oral y, más en concreto, en la de los cancioneros populares.

\section{Esquema interpretativo de Draghi- Lucero, Castilla y Gatica}

En lo atinente al desarrollo establecido, la interpretación de Mannina de Gamero (parte II) está en favor de los tres autores del corpus y contempla para cada uno una semblanza biobliográfica, acompañada de una recopilación de sus obras y, a su vez, por la significación fundamental de sus elaboraciones acerca de una estética que, asentada en la idea de andinidad, se caracterice por incluir la unidad diferenciada de un silencio originario devenido palabra poética. Como ya se ha dicho, este estudio se condice con una actitud agonal en la que los dos conceptos operatorios de silencio y de palabra pugnan por su cabal expresión. El abordaje hermenéutico de este proceso es, en definitiva, el derrotero propuesto por el itinerario que aquí se estudia.

\section{Draghi-Lucero y el silencio del Ande}

En el caso de Juan Draghi-Lucero, el silencio hecho palabra toma cuerpo a través de sus poemarios: Novenario cuyano (1935), Al pie de la serranía (1966) y Antología poética (1990). Pero fundamentalmente a través de su obra narrativa más famosa, Las mil y una noches argentinas (1939), pues en esta el cuento folclórico se cumple como un juego dialéctico de la ipseidad. Este juego resulta de la conjunción entre la religión y la ética con las posibilidades semánticas del lenguaje simbólico, que pertenece al mito. Desde el material presignificante que implica el "silencio del Ande" - tal como se titula el apartado dedicado por Mannina de Gamero (59ss.) a Draghi-Lucerola apertura a lo maravilloso instaura una dimensión numinosa en la que se inserta el eterno conflicto entre el bien y el mal, esencia del relato de Las mil y una noches argentinas. Esto mismo permite una recuperación de los valores erigidos desde el horizonte de la identidad y, a partir de ella, de la eticidad ínsita a esa experiencia participativa de naturaleza religiosa a la vez que primordial (Mannina de Gamero 69ss.).

\section{Castilla y el silencio de quien goza}

En cuanto a la figura de Manuel J. Castilla, Mannina de Gamero (85 ss.) ahonda en el sesgo particular que 
articula la poética y "el silencio del gozante", expresión deudora de una de las obras ejemplares del autor salteño: Cantos del gozante (1972). Junto con Luna muerta (1943), La niebla y el árbol (1946), Copajira (1949), La tierra de uno (1951), Norte adentro (1954), De solo estar (1957), El cielo lejos (1959), Bajo las lentas nubes (1963) y Posesión entre pájaros (1966), entre otros poemarios, constituye una de las contribuciones más sólidas y ricas a la poesía argentina contemporánea. La producción castillana, refiere Mannina de Gamero, se relaciona con la propuesta estética de una instauración originaria en el mundo de la vida sobre la base de supuestos teóricos nítidamente circunscritos a la región (La Carpa y el Noroeste Argentino) y en el contexto de la problemática mundial latinoamericana, propia de la generación del 40 . El horizonte de sentido de esta poesía se organiza a partir de una serie de notas que Mannina de Gamero (110-114) sintetiza mediante los siguientes predicados: "indigenismo de vanguardia", "literatura de frontera" "herencia surrealista" y "sentido de región".

Con respecto a los núcleos temáticos que articula la obra de Castilla, sobresale una "ontología del tiempo", en la medida en que su afianzamiento poético "[...] se cumple como experiencia estética de apertura del ser en el mundo, del habitar que se hace palabra en un despliegue espiralado de ahondamiento creciente en su centro fundante" (Mannina de Gamero 115). De esta ontología resulta un tiempo agonal, enfocado hacia el horizonte de una "ontología del ahora" entendida como un "[...] tratamiento poético del área mundana de significatividad poética, la tierra-vida, desde el tiempo kairológico del ahora" (Mannina de Gamero 122).

Sobre la base de esta plenitud del gozo, el sujeto lírico se autoconfigura en una actividad tendida entre la inmediatez de lo dado y la mediación de la fuerza espiritual. Tal es así que "[p]or la operatividad creadora de la existencia-consciencia hacedora de sentido y belleza, se fecunda la ignorancia y se purga la sensorialidad en un parto de dolor y amor conjugados por la fidelidad del perseverar en el ser" (Mannina de Gamero 123). Esta tensión compete tanto a la percepción como a la memoria, al presente como al pasado. Se expresa en la poesía de Castilla como el allí del encuentro, el cuándo autoconvocado de las raíces y la luz, y el espacio propio subsumido por un tiempo ontológico (Mannina de Gamero 123-129).
Siguiendo este orden de ideas, cabe aclarar que el ciclo indigenista de Castilla va en busca de un criterio de autonomía que le permita alejarse de la pasiva ingenuidad romántica, no menos que del activismo estéril materialista. Llega, entonces, a la instancia de andinidad y a la práctica de un vanguardismo de su propia cosecha, por medio del cual se potencia el costado social de su literatura (Mannina de Gamero 189-191).

\section{Gatica y el silencio de los llanos}

En cuanto al tercero de los autores elegidos, Héctor Gatica, se destaca "[...] el silencio de los Llanos" (Mannina de Gamero 131ss.) como hontanar de sentido que se registra en sus obras: Memoria de los Llanos (1961) con sus once ediciones, Los días del amor (1986), Los días insólitos (1986), El canto del amor (1988), País desvelado (1988) y La cantata riojana (2001). También, en los cuentos de Los fundadores del olvido (1989), El canto del canario (2007) o en el libro de memorias La carpeta vacía (2006). Entre otras aportaciones, Gatica plantea la relación identitaria con el canto como modo de manifestación de un vivir en comunión cósmica. Se pueden distinguir en su pluma los siguientes matices: la tradición del canto del incario; la tradición hispánica épica y lírica de los romances traídos por los conquistadores, y la incorporación del elemento africano como resultado del mestizaje que signa los años augurales de América. El conjunto de estos caracteres confluye en la composición de la Cantata (Mannina de Gamero 155ss.).

De esa obra, la autora analiza con singular maestría tres actos o momentos que dan forma al drama íntegro de una tierra: partiendo desde su fundación poiética hasta un presente de esperanza, pasando por los agitados tiempos del alumbramiento de la América mestiza. En relación con esta lectura genética y axiológica del suelo americano, Mannina de Gamero expresa que "[d]el fondo del silencio de la memoria se yergue la figura de la ciudad fiel a su identidad geográfica y cultural, la que ha aprendido a sobrevivir a sus propias muertes [...]" (178). Se celebra con este poema una épica y se dibuja un territorio donde las heroicidades cotidianas, la gesta histórica con sus improvisados mártires y el aroma del naranjo se enlazan en una trama, que regala el canto de la torcaz desde el silencio de un cerro andino (Mannina de Gamero 191). 


\section{Conclusión}

La hipótesis de la que partía este trabajo era que el estudio elaborado por Mannina de Gamero acerca de una estética de la andinidad contribuye a replantear, sobre la base conceptual del binomio poetizar y pensar, la pregunta existencial por la identidad y el reconocimiento histórico que presupone todo fenómeno educativo situado en América Latina. Puede decirse entonces que nuestro artículo ha dilucidado de qué manera la investigación de la autora promueve la consolidación de una estética que se materializa en la obra poética de los tres autores argentinos: DraghiLucero, Castilla y Gatica. Se ofrece mediante esto una propuesta teórica incitante sobre el problema educativo de la identidad y de la reconciliación histórica, subyacentes a la profunda hendidura de la conquista americana. En un sentido metodológico, este artículo ha realizado la hermenéutica de una contribución que, desde la perspectiva de lo regional y afincada en raíces ancestrales, despliega su riqueza existencial a fuerza de alternar silencio y voz. Asimismo, hay que señalar que si bien se destaca el rigor analítico con que Mannina de Gamero ha sabido penetrar en el discurso de los tres autores seleccionados, se muestra peculiarmente idónea al congeniar mirada nutrida en la filosofía con fina sensibilidad para la captación de valores poéticos. Su lenguaje es perfectamente asequible no solo al público universitario especializado, sino también a los estudiantes y docentes que deseen entregarse a la lectura placentera de la poética de aquellos autores andinos, mediante la orientación que les brinde un estudio de referencia como el que aquí tratamos. Por todo lo expuesto, se colige que la temática elucidada a lo largo de este trabajo acrecienta el conocimiento de literatura, y permite a su vez seguir preguntando por la dimensión existencial y el compromiso con la cultura de la ipseidad, inherentes a toda situación educativa latinoamericana. Solamente desde un preguntar semejante la formación personal o comunitaria podrá hacerse cargo de cada individuo en cuanto ser histórico, con memoria de su pasado y abierto a la posibilidad de consolidar un humanismo gozoso, de enjundia ética. Así lo expresa Atahualpa Yupanqui ("Destino del canto") con ánimo sereno no menos que esperanzado:

Nada resulta superior al destino del canto.

Ninguna fuerza abatirá sus sueños.

Renacen -los poetas- cada día, para ser.
Sí, la tierra señala a su elegido.

El alma de la tierra, como una sombra, sigue a los seres indicados para traducirla en la esperanza, en la pena, en la soledad.

La luz que alumbra el corazón del artista es una lámpara milagrosa que el poeta usa para encontrar la belleza en el camino.

\section{Referencias}

Aristóteles. Metafísica. Ed. trilingüe de Valentín García Yebra. Madrid: Gredos, 1998. Impreso.

Barcia, Pedro L. "Hacia un concepto de la literatura regional". Literatura de las regiones argentinas. Eds. Gloria Videla de Rivero y Marta Castellino. Mendoza: Universidad Nacional de Cuyo, 2004. Impreso.

Becco, Horacio J. Cancionero tradicional argentino. Buenos Aires: Hachette, 1960. Impreso.

Cortázar, Augusto R. "Los fenómenos folklóricos y su contexto humano y cultural". Teoría del folklore en América Latina. Venezuela: Inidef, 1978. Impreso.

Dávalos, Juan Carlos. Cuentos y relatos del norte argentino. Buenos Aires: La Crujía, 2009. Impreso.

Heidegger, Martin. Aportes a la filosofía: acerca del evento. Trad. Dina Picotti. Buenos Aires: Biblos, 2006. Impreso

-. Ser y tiempo. Trad., pról. y notas Jorge Eduardo Rivera. Santiago de Chile: Editorial Universitaria, 1997. Impreso.

Kush, Rodolfo. América profunda. Buenos Aires: Hachette, 1962. Impreso.

MacIntyre, Alasdair. Tres versiones rivales de la ética. Trad. R. Rovira. Madrid: Rialp, 1992. Impreso.

Mannina de Gamero, Liliana. El silencio andino: huella de identidad. Hacia una estética de la andinidad. Mendoza: Edifyl; Allubgraf, 2015. Impreso.

Ricœur, Paul. Caminos del reconocimiento. México: Fondo de Cultura Económica, 2006. Impreso.

-. Ideología y utopía. Barcelona: Gedisa, 2001. Impreso.

-. "La identidad narrativa". Historia y narratividad. Barcelona: Paidós, 1999. Impreso.

-. Sí mismo como otro. México: Siglo xxi, 1996. Impreso.

-. Tiempo y narración. México: Siglo xxI, 1996. Impreso.

Roig, Arturo A. Teoría y crítica del pensamiento latinoamericano. Buenos Aires: Una Ventana, 2009. Impreso.

Yupanqui, Atahualpa. "Destino del canto". El canto del viento. Vol. 1. Buenos Aires: Honegger, 1965. Impreso. 